\title{
Effect of cell-penetrating peptide-coated nanostructured lipid carriers on the oral absorption of tripterine
}

This article was published in the following Dove Press journal:

International Journal of Nanomedicine

17 August 2012

Number of times this article has been viewed

\author{
Yan Chen' \\ Ling Yuan ${ }^{2}$ \\ Lei Zhou ${ }^{2}$ \\ Zhen-hai Zhang' \\ Wei $\mathrm{CaO}^{2}$ \\ Qingqing $W_{u^{2}}$
}

'Key Laboratory of New Drug Delivery System of Chinese Materia Medica, Jiangsu Provincial Academy of Chinese Medicine, Nanjing, Jiangsu, People's Republic of China; ${ }^{2}$ Department of Pharmaceutics, School of Pharmacy, Jiangsu University, Zhenjiang, Jiangsu, People's Republic of China
Correspondence: Yan Chen Key Laboratory of New Drug Delivery System of Chinese Materia Medica, Jiangsu Provincial Academy of Chinese Medicine, 100 Shizi Road, Nanjing, Jiangsu 210028, People's Republic of China

Tel +862585608672

Fax +862585637809

Email ychen202@yahoo.com.cn
Purpose: To develop nanostructured-lipid carriers (NLCs) coated with cell-penetrating peptides (CPP) for improving the oral bioavailability of tripterine.

Methods: We prepared CPP-coated tripterine-loaded NLCs (CT-NLCs) by using a solvent evaporation method, and determined their physical properties. In vitro drug release was determined by using a dialysis bag diffusion technique, and intestinal toxicity was evaluated by performing MTT assay using Caco- 2 cells. In vivo absorption was studied in an in situ rat intestinal perfusion model, and oral bioavailability was examined in beagles.

Results: The average particle size, zeta potential, and encapsulation efficiency of the optimized CT-NLCs were $126.7 \pm 9.2 \mathrm{~nm}, 28.7 \pm 3.4 \mathrm{mV}$, and $72.64 \% \pm 1.37 \%$, respectively. The CT-NLCs showed a controlled release profile in vitro and had significantly lower intestinal cytotoxicity than the tripterine solution $(P<0.05)$. The absorption levels of tripterine from the CT-NLCs in the rat duodenum and jejunum were markedly higher than with tripterine-loaded NLCs without the CPP coating (T-NLCs), and with tripterine solution. Pharmacokinetic study showed that the maximum concentration of the CT-NLCs was greater than that of the T-NLCs and tripterine suspension, and that the time to maximum concentration of the CT-NLCs as well as the T-NLCs, was longer than that of the tripterine suspension. The relative oral bioavailability of the CT-NLCs compared to that of tripterine suspension and T-NLCs were $484.75 \%$ and $149.91 \%$ respectively.

Conclusion: The oral bioavailability of tripterine is dramatically increased by CT-NLCs. Therefore, CT-NLCs seem to be a promising carrier for oral delivery of tripterine.

Keywords: cell-penetrating peptides, nanostructured lipid carriers, tripterine, oral drug delivery, bioavailability

\section{Introduction}

Tripterine, also known as celastrol, is isolated from the thunder god vine (Tripterygium wilfordii Hook f). ${ }^{1}$ Tripterine is generally used to treat autoimmune diseases, ${ }^{2}$ allergic asthma, ${ }^{3}$ rheumatoid arthritis, ${ }^{4}$ and neurodegenerative disease. ${ }^{5}$ Recently, tripterine has attracted great interest because it is a natural proteasome inhibitor that exhibits promising effects in human malignancies. ${ }^{6,7}$ However, tripterine is poorly soluble and is not readily absorbed into the bloodstream, and therefore has low oral bioavailability. At the same time, oral administration of large doses of tripterine can have severe side effects on the gastrointestinal tract (GIT), kidneys, and reproductive system. ${ }^{8-10}$ To overcome these deficiencies, formulations that improve the oral absorption of tripterine in the GIT and reduce its side effects, are required.

Nanostructured lipid carriers (NLCs) are a new generation of lipid nanoparticles produced by the controlled mixing of solid lipids with spatially incompatible liquid 
lipids, which lead to special nanostructures. ${ }^{11}$ NLCs loaded with poorly water-soluble drugs (eg, etoposide) can improve their oral bioavailability ${ }^{12}$ and reduce the side effects of these drugs. ${ }^{13}$ Previously, we showed that NLCs can improve the dissolution properties of tripterine and promote its intestinal absorption. ${ }^{14}$ However, the absorption of lipid nanoparticles continued to be limited, only occurring via the transcellular pathway by M cells in Peyer's patches or by pinocyt osis in the GIT. ${ }^{15}$

Cell-penetrating peptides (CPPs) are short and mostly cationic and/or amphiphilic peptides that can transport micromolecules and macromolecules, including nanoparticles, across cell membranes. ${ }^{16}$ CPPs are rich in basic amino acids such as arginine, lysine, and leucine, and are thought to be absorbed predominantly via endocytosis and translocation. ${ }^{17}$ These peptides are capable of internalizing electrostatically or covalently bound, biologically active cargoes such as several proteins, ${ }^{18}$ oligonucleotides, ${ }^{19}$ solid lipid nanoparticles (SLNs), ${ }^{20}$ and liposomes ${ }^{21}$ with high efficiency and low toxicity. ${ }^{22,23}$ One study showed that CPP-coated SLNs could be a promising per-oral carrier for oral administration of insulin. ${ }^{24}$ Therefore, we speculated that CPPs might be useful for facilitating the delivery of tripterine-loaded NLCs (T-NLCs) in enterocytes.

The objective of our study was to improve the oral bioavailability of tripterine by developing CPP-coated T-NLCs (CT-NLCs). Ste- $\mathrm{R}_{6} \mathrm{~L}_{2}$, a new kind of CPP, was used for its lipophilic character, high stability, and lack of hygroscopicity. We prepared and characterized CT-NLCs and T-NLCs and then compared their cytotoxicity, cellular uptake, intestinal absorption, and pharmacokinetic behavior. We speculated that the oral bioavailability of tripterine might be further increased by using a CT-NLC formulation, and that CT-NLCs might be a promising oral delivery system for tripterine.

\section{Materials and methods \\ Materials}

Tripterine (purity $>99 \%$ ) was purchased from ZeLang Medicine Technology Co, Ltd (Nanjing, China). Prednisolone (purity $>99 \%$ ) was purchased from the National Institute for the Control of Pharmaceutical and Biological Products (Beijing, China). Precirol ATO-5 (solid lipid) and Labrafil M 1944CS (liquid lipid) were obtained from Gattefossé (Lyon, France). Poloxamer 188 (Pluronic F68, F68), Hanks' balanced salt solution (powder form), D- $\alpha$-tocopherol polyethylene glycol succinate 1000, 3-(4,5-dimethylthiazol-2-yl)-2,5diphenyltetrazolium bromide (MTT), and dimethyl sulfoxide were purchased from Sigma-Aldrich (St Louis, MO). Soybean lecithin (SLT) was supplied by Shanghai Advanced Vehicle Technology Co (Shanghai, China). Dialysis bags (molecular weight cutoff 8-14 kDa) were supplied by Union Carbide Corp (Chicago, IL). All other chemicals were of reagent grade and were used without additional purification. Ste- $\mathrm{R}_{6} \mathrm{~L}_{2}$ (Ste-RRRRRRLL, purity > 97\%) was synthesized by GL Biochem Ltd (Shanghai, China) by a solid-phase synthesis method. All reagents were of analytical or high-performance liquid chromatography (HPLC) grade. Double-distilled water was prepared in our laboratory.

\section{Animals and cell lines}

Caco- 2 cells were donated by Dr Ming Hu from the University of Houston (Houston, TX). Cells were grown at $37^{\circ} \mathrm{C}$ in culture medium composed of Dulbecco's modified Eagle's medium supplemented with $20 \%$ fetal calf serum, $1 \%$ nonessential amino acids, $100 \mathrm{U} / \mathrm{mL}$ penicillin, and $100 \mu \mathrm{g} / \mathrm{mL}$ streptomycin, in a humidified atmosphere of $5 \% \mathrm{CO}_{2}$.

Male Sprague-Dawley rats weighing 200-250 g were obtained from the Shanghai Laboratory Animal Center (Shanghai, China). Beagles weighing 9-11 kg were obtained from the Animal Center of the Jiangsu Provincial Academy of Chinese Medicine (Nanjing, China). The animal experiment protocol was reviewed and approved by the Institutional Animal Care and Use Committee of the Jiangsu Provincial Academy of Chinese Medicine.

\section{Preparation of NLCs}

T-NLCs were prepared by solvent evaporation. The composition of the T-NLC dispersion is presented in Table 1.

Table I Compositions of the different NLC formulations

\begin{tabular}{|c|c|c|c|c|c|c|c|c|}
\hline Formulation & $\begin{array}{l}\text { Tripterine } \\
(\mathrm{mg})\end{array}$ & $\begin{array}{l}\text { CPP } \\
(\mathrm{mg})\end{array}$ & $\begin{array}{l}\text { Precirol } \\
\text { ATO-5 (mg) }\end{array}$ & $\begin{array}{l}\text { Labrafil M } \\
\text { I944CS (mg) }\end{array}$ & $\begin{array}{l}\text { SLT } \\
(\mathrm{mg})\end{array}$ & $\begin{array}{l}\text { TPGS } \\
(\mathrm{mg})\end{array}$ & $\begin{array}{l}\text { F68 } \\
(\%) \\
\end{array}$ & $\begin{array}{l}\text { Water } \\
(\mathrm{mL})\end{array}$ \\
\hline T-NLC & 30 & $\mathrm{n} / \mathrm{a}$ & 360 & 120 & 60 & 60 & 0.5 & 50 \\
\hline CT-NLC-I & 30 & 15 & 360 & 120 & 60 & 60 & 0.5 & 50 \\
\hline CT-NLC-2 & 30 & 30 & 360 & 120 & 60 & 60 & 0.5 & 50 \\
\hline CT-NLC-3 & 30 & 45 & 360 & 120 & 60 & 60 & 0.5 & 50 \\
\hline
\end{tabular}

Abbreviations: NLC, nanostructured lipid carrier; T-NLC, tripterine-loaded NLC; CT-NLC, cell-penetrating peptide-coated T-NLC; SLT, soybean lecithin; TPGS, D- $\alpha$-tocopherol polyethylene glycol succinate 1000; n/a, not applicable. 
Precirol ATO-5 and Labrafil M 1944CS (3:1, w/w) were selected as the solid and liquid matrices, respectively, to form NLCs. SLT and D- $\alpha$-tocopherol polyethylene glycol succinate 1000 were used as emulsifiers. ${ }^{25}$ Lipids, emulsifiers, and tripterine were dissolved in $12 \mathrm{~mL}$ of an organicphase acetone-alcohol mixture $(3: 1, \mathrm{v} / \mathrm{v})$ to form the oil phase. The aqueous phase was prepared by dispersing the surfactant (F68, $0.5 \mathrm{wt} \%$ ) in $50 \mathrm{~mL}$ double-distilled water. The oil and aqueous phases were maintained in a water bath at $60^{\circ} \mathrm{C}$. At this temperature, the oil phase was rapidly injected into the stirred aqueous phase (1000 rpm). The resulting suspension was continually stirred at $60^{\circ} \mathrm{C}$ for 4 hours at $400 \mathrm{rpm}$. After the organic solvents were removed, the nanoemulsion was stirred in an ice bath for 2 hours to stabilize the T-NLCs. The T-NLCs were then harvested and stored at $4^{\circ} \mathrm{C}$.

For the CT-NLC dispersions, different amounts of Ste- $\mathrm{R}_{6} \mathrm{~L}_{2}$ were added to $50 \mathrm{~mL}$ of $0.5 \mathrm{wt} \% \mathrm{~F} 68$ solution to form the aqueous phase; the other procedures were the same as those for the preparation of T-NLCs. We prepared three CT-NLC formulations with different CPP-to-tripterine ratios: $1: 2,2: 2$, and $3: 2$.

\section{Characterization of CT-NLCs and T-NLCs} Particle size and zeta potential

The particle size and polydispersity index (PDI) of the CT-NLCs and T-NLCs were measured by photon correlation spectroscopy (Zetasizer Nano ZS ZEN3600; Malvern Instruments $\mathrm{Ltd}$, Worcestershire, UK) at $25^{\circ} \mathrm{C}$ under a fixed angle of $90^{\circ}$ in polystyrene cuvettes. The zeta potential was analyzed using the Nano-ZS Zetasizer by electrophoretic light scattering. The samples were placed in the measurement cells. Each measurement was performed in triplicate.

\section{Entrapment efficiency}

Ultrafiltration was used to assay the entrapment efficiency (\%EE). Briefly, $0.5 \mathrm{~mL}$ of an undiluted sample was placed in the inner chamber of a centrifuge tube matched with an ultrafilter (molecular weight cutoff $12 \mathrm{kDa}$; Pall Corp, Port Washington, NY). The filter assembly was then centrifuged at $5000 \mathrm{rpm}(\sim 3000 \mathrm{~g})$ for 15 minutes. Encapsulated tripterine remained in the inner chamber, whereas the ultrafiltrate containing unloaded tripterine moved to the outer chamber through the filter membrane. The amount of tripterine present in the outer chamber $\left(W_{\text {free }}\right)$ was determined by HPLC. Further, an equal volume of tripterine-loaded NLC dispersion was dissolved and diluted with methanol. Then, the total tripterine content in the resultant solution $\left(W_{\text {total }}\right)$ was determined by HPLC. The \%EE was calculated using the following equation: ${ }^{26}$

$$
\% \mathrm{EE}=\frac{W_{\text {total }}-W_{\text {free }}}{W_{\text {total }}} \times 100
$$

For all HPLC analyses, the HPLC system (Agilent Technologies, Santa Clara, CA) consisted of a binary pump, an autosampler, and a diode array detector. An Agilent SB-C18 column $(4.6 \mathrm{~mm} \times 150 \mathrm{~mm}, 5 \mu \mathrm{m})$ was used as the stationary phase. Tripterine was determined by HPLC at $426 \mathrm{~nm}$. The mobile phase was a mixture of acetonitrile $-0.4 \%$ phosphoric acid $(80: 20, \mathrm{v} / \mathrm{v})$ at a flow rate of $1 \mathrm{~mL} / \mathrm{min}$.

\section{Transmission electron microscopy}

Morphology of the nanoparticle formulation was observed by transmission electron microscopy (TEM) (Tecnai 12; Royal Philips Electronics, Eindhoven, The Netherlands). After diluting the formulations with double-distilled water, a drop of sample was placed onto a copper grid coated with carbon film followed by negative staining with $2 \%$ phosphotungstic acid. All samples were air dried before the TEM observations.

\section{Differential scanning calorimetry}

Recrystallization index was evaluated by differential scanning calorimetry (DSC 204; Netzsch, Selb, Germany). The samples for thermal analysis were as follows: (1) tripterine; (2) CPP; (3) physical mixture I (Precirol ATO-5, Labrafil M 1944CS, SLT, DPGS, and F68); (4) physical mixture II (Precirol ATO-5, Labrafil M 1944CS, SLT, DPGS, F68, tripterine, and CPP); (5) T-NLCs; and (6) CT-NLCs. All samples were freeze-dried before the measurements. Each sample (10 mg) was placed in an aluminum pan, and an empty pan was used as the reference. During the scanning process, a heating rate of $10^{\circ} \mathrm{C} / \mathrm{min}$ was applied over a range of $25^{\circ} \mathrm{C}-300^{\circ} \mathrm{C}$ Each measurement was performed in triplicate.

\section{In vitro drug-release assay}

A dialysis bag diffusion technique was utilized to compare the in vitro drug release of the CT-NLCs and T-NLCs. A sample $(2 \mathrm{~mL})$ of each formulation was placed into a dialysis bag with a molecular weight cutoff of 8-14 kDa. Each bag was immersed in $20 \mathrm{~mL}$ release medium $(20 \%$ ethanol in phosphate-buffered saline, $\mathrm{pH}$ 7.4), which was used to maintain appropriate sink conditions. The medium was stirred at $100 \mathrm{rpm}$ and maintained at $37^{\circ} \mathrm{C} \pm 0.5^{\circ} \mathrm{C}$. At $2,4,8,10,12,18,24,36$, and 48 hours; a $1 \mathrm{~mL}$ dispersion sample was withdrawn and replaced with the same volume of fresh medium so that a constant volume 
was maintained. The amount of in vitro drug release was determined by HPLC as described earlier. The experiments were performed in triplicate for each formulation.

\section{MTT assay}

We performed MTT assay to investigate in vitro intestinal toxicity of the antiparticle formulations; we used Caro- 2 cells for this assay. Caco- 2 cells were seeded at $4 \times 10^{3}$ cells/well into 96 -well culture plates and were incubated at $37^{\circ} \mathrm{C}$ for 24 hours before the assay. The cells were divided into three treatment groups: those treated with (a) CT-NLCs, (b) T-NLCs, and (c) tripterine solution (dimethyl sulfoxide $<0.1 \%$ ). In each group, $10 \mu \mathrm{L}$ of test solution was added to each well, and the cells were exposed to a series of doses $(0.1-2.0 \mu \mathrm{g} /$ $\mathrm{mL}$ ). After 24 hours of incubation, $20 \mu \mathrm{L}$ of MTT (5 mg/ $\mathrm{mL}$ ) was added to each well and the cells were incubated for another 4 hours. After removing the culture medium, $100 \mu \mathrm{L}$ of dimethyl sulfoxide was added to dissolve the contents in the plate. Then, the absorbance was measured at 570 and $630 \mathrm{~nm}$ (reference wavelength) using a microplate reader (Multiskan MK3; Thermo Fisher Scientific, Waltham, MA). ${ }^{27}$ The experiments were performed in triplicate. The drug concentration that caused $50 \%$ inhibition $\left(\mathrm{IC}_{50}\right)$ was calculated by plotting the percentage of cell survival as a function of the drug concentration using SPSS 17.0 (IBM Corporation, Armonk, NY) with the probit model.

\section{Evaluation of cellular uptake}

Caco-2 cells $\left(5 \times 10^{5}\right)$ were grown in $25 \mathrm{~cm}^{3}$ plastic flasks at $37^{\circ} \mathrm{C}$. Once the bottom of the flask was completely covered by a dense layer of cells, the medium was discarded and the cells were washed three times with sterile phosphate-buffered saline. Then, the cells were treated with $6 \mathrm{~mL}$ of CT-NLC, and T-NLC formulations ( $1 \mu \mathrm{g} / \mathrm{mL})$ diluted in Dulbecco's modified Eagle's medium. After incubation for 1, 2, 3, and 4 hours, the cells were washed three more times with phosphatebuffered saline ( $\mathrm{pH}$ 7.2), and were removed from the culture flasks using disposable cell scrapers. The cells were lysed by using an ultrasonic cell pulverizer (JY92-IIN; Ningbo Scientz Biotechnology Co, Ltd, Ningbo City, China) and then were centrifuged again at $15,000 \mathrm{rpm}$ for 15 minutes at $4^{\circ} \mathrm{C}$. The tripterine content of the cells $\left(W_{i n}\right)$ was determined by HPLC. $W_{\text {total }}$ was the total tripterine content in the culture medium. The percentage of cellular uptake by the test sample $(n=3)$ was calculated using the following equation:

$$
\text { Cellular uptake }(\%)=\frac{W_{\text {in }}}{W_{\text {total }}} \times 100
$$

\section{In situ rat intestinal perfusion assay}

The intestinal surgical procedures on the intestine were performed as previously described.$^{27}$ Briefly, Sprague-Dawley rats $(n=4)$ were anesthetized with an intraperitoneal injection of urethane $(0.5 \mathrm{~g} / \mathrm{mL})$ at a dose of $0.28 \mathrm{~mL} / 100 \mathrm{~g}$. Each of the 4 intestinal segments - the duodenum, jejunum, ileum, and colon (8-12 cm of each part) - were simultaneously cannulated using 2 cannulas. The segments were carefully placed into the abdominal cavity, avoiding crimping or kinking. Perfusion was performed using an infusion pump (PHD 2000; Harvard Apparatus, Inc, Holliston, MA) at a flow rate of $0.15 \mathrm{~mL} / \mathrm{min}$ with $20 \mu \mathrm{M}$ of the drug in a Hanks' balanced salt solution solution ( $\mathrm{pH} 7.4)$. To maintain the temperature of the perfusate constant, the inlet cannulate was insulated and kept warm by a circulating water bath at $37^{\circ} \mathrm{C}$. After a 30 -minute washout with the perfusate, perfusate samples from the four sites were collected every 30 minutes for up to 2 hours. Once the perfusion was complete, the length of each intestinal segment was measured and each sample-containing tube was weighed. The outlet concentrations of tripterine in the perfusate were determined by HPLC.

Effective permeability $\left(P_{\text {eff }}^{*}\right)$ and the percent absorption of $10 \mathrm{~cm}$ of intestine $(10 \mathrm{~cm} \% \mathrm{ABS})$ are parameters representing the intestinal membrane permeability. $P_{\text {eff }} *$ and $10 \mathrm{~cm} \% \mathrm{ABS}$ of the compounds were calculated using the following equations:

$$
\begin{gathered}
P_{\mathrm{eff}} *=\frac{1-C_{m} / C_{o}}{4 G_{z}} \\
10 \mathrm{~cm} \% \mathrm{ABS}=\frac{\left(1-Q_{m} / Q_{o}\right) \times 10}{V L}
\end{gathered}
$$

where $C_{\mathrm{o}}$ and $C_{\mathrm{m}}$ are the inlet and outlet concentrations, respectively; $G_{z}$, or Graetz number $\left(G_{z}=\pi D L / 2 R\right)$, is a scaling factor that incorporates flow rate $(R)$, intestinal length $(L)$, and diffusion coefficients (D) to make permeability dimensionless; $Q_{\mathrm{m}}$ and $Q_{\mathrm{o}}$ are the inlet and outlet drug contents, respectively; $V$ is related to flow rate $(R)$ and water flux. $C_{\mathrm{m}}$ was adjusted for water flux.

\section{Pharmacokinetic study in beagles}

Six healthy beagles, fasted but with free access to water for 12 hours before the experiment, were used in the study. We performed a three-period randomized crossover study. The washout period between consecutive treatment schedules was 1 week. $^{28}$ The dogs were orally administered three test 
formulations: tripterine suspension (tripterine dispersed in $5 \%$ sodium carboxymethyl cellulose solution), CT-NLCs, and T-NLCs. The dosage of tripterine was $1.5 \mathrm{mg} / \mathrm{kg}$. After administration, blood samples $(\sim 2 \mathrm{~mL})$ were collected from the forelimb vein of the dogs at $0.25,0.5,0.75,1,2,3,4,6$, $8,10,12$, and 24 hours. Plasma samples were harvested by centrifugation at $3000 \mathrm{rpm}$ for 10 minutes and were stored at $-20^{\circ} \mathrm{C}$ until analysis.

The plasma samples were prepared by mixing $500 \mu \mathrm{L}$ of plasma with $20 \mu \mathrm{L}$ of the internal standard (prednisolone, $2.5 \mu \mathrm{g} / \mathrm{mL}$ ). The mixture was extracted with $2 \mathrm{~mL}$ of dichloromethane and 120 seconds of vortexing. After 10 minutes of centrifugation at $3000 \mathrm{rpm}$, the organic layer was transferred to another clean tube and extracted again. The resulting organic layer was evaporated under nitrogen at $40^{\circ} \mathrm{C}$. The residue was reconstituted with $100^{\circ} \mu \mathrm{L}$ of the mobile phase by vortexing for 5 minutes, and $20^{\circ} \mu \mathrm{L}$ of the solution was analyzed by HPLC. Calibration curve was constructed by using the peak-area ratio (tripterine peak area to the internal standard peak area) to the concentration $(\mathrm{C}, \mu \mathrm{g} / \mathrm{mL})$, and it provided a reliable response from $0.05-2.0^{\circ} \mu \mathrm{g} / \mathrm{mL}$. The calibration curve was $\mathrm{A}=0.0074 \mathrm{C}-0.0778(\mathrm{r}=0.9981)$. The lower limit of quantification for the determination of tripterine in dog plasma was $25 \mu \mathrm{g} / \mathrm{L}$. Both the intra- and interday precisions were $<8 \%$. The mean recovery of tripterine at low, medium, and high concentrations $(0.05,0.20$, and $1.0 \mu \mathrm{g} /$ $\mathrm{mL}$, respectively) exceeded $60 \%$ (range, $64.25 \%-68.16 \%$ ). The main pharmacokinetic parameters were acquired by noncompartmental pharmacokinetic analysis using a pharmacokinetic program (DAS 2.1.1; Mathematical Pharmacology Professional Committee of China, Shanghai, China). The area under the concentration-time curve (AUC) was calculated by the linear trapezoidal method. The relative bioavailability of each formulation was calculated using the following formula: ${ }^{29}$

$$
F_{r e l}(\%)=\frac{\mathrm{AUC}_{t} \times \mathrm{D}_{r}}{\mathrm{AUC}_{r} \times \mathrm{D}_{t}} \times 100
$$

where $F_{r e l}$ is the relative bioavailability; $\mathrm{AUC}_{t}$ and AUC represent $\mathrm{AUC}_{(0-t)}$ of the test and reference formulations, respectively, and $\mathrm{D}_{r}$ and $\mathrm{D}_{t}$ are the doses of the test and reference formulations, respectively.

\section{Statistical analysis}

Data were analyzed using SPSS version 17.0. One-way analysis of variance was used for multiple comparisons, and Student's $t$-test was used to compare two groups. A value of $P<0.05$ was considered statistically significant. All values were expressed as means \pm standard deviation (SD).

\section{Results Physicochemical characteristics}

The particle sizes and surface charges of the CT-NLCs and T-NLCs are shown in Table 2. The particle sizes of the CT-NLCs, which varied from $115.9 \pm 10.4-188.8 \pm 17.1 \mathrm{~nm}$, were consistently greater than those of the T-NLCs, with an average particle size of $102.4 \pm 12.8 \mathrm{~nm}$. Before coating with the CPP, the T-NLCs had a zeta potential of $-26.2 \pm 2.73 \mathrm{mV}$. The zeta potential of the nanoparticle dispersion was reversed after the CPP coating, and it increased to $13.6 \pm 1.2 \mathrm{mV}$ (with $15 \mathrm{mg}$ of coating) and $31.0 \pm 2.3 \mathrm{mV}$ (with $45 \mathrm{mg}$ of coating). The PDIs of the CT-NLCs with different amounts of the CPP, ranged from $0.142 \pm 0.032-0.196 \pm 0.037$, and were below 0.2 ; the T-NLCs had a PDI of $0.129 \pm 0.028$. The $\%$ EEs of the CT-NLCs and T-NLCs were about 70\%, ranging from $69.10 \%-74.64 \%$. Comparison of the zeta potentials, PDIs, and \%EEs of the three CT-NLC formulations indicated that CT-NLC-2 was the most promising formulation. Therefore, CT-NLC-2 was selected as the optimized formulation for further studies.

\section{Morphology and crystal form}

TEM showed that all the T-NLC and CT-NLC particles had spherical or ellipsoidal shapes and did not stick to each other (Figure 1). The DSC curves of tripterine, CPP, physical mixture I, physical mixture II, T-NLCs, and CT-NLC lyophilized powder are shown in Figure 2. Thermograms showed two melting peaks for tripterine $\left(175.7^{\circ} \mathrm{C}\right.$ and $\left.211.4^{\circ} \mathrm{C}\right)$ and the $\mathrm{CPP}$

Table 2 Particle size, zeta potential, and entrapment efficiency of the T-NLC and CT-NLC formulations

\begin{tabular}{lllrll}
\hline Formulation & CPP/tripterine ratio & Average size $(\mathbf{n m})$ & Zeta potential $(\mathbf{m V})$ & PDI & EE $(\%)$ \\
\hline T-NLC & $0: 1$ & $102.4 \pm 12.8$ & $-(26.2 \pm 2.7)$ & $0.129 \pm 0.028$ & $74.64 \pm 0.87$ \\
CT-NLC-I & $1: 2$ & $115.9 \pm 10.4$ & $(13.6 \pm 1.2)$ & $0.187 \pm 0.041$ & $73.76 \pm 0.64$ \\
CT-NLC-2 & $2: 2$ & $126.7 \pm 9.2$ & $(28.7 \pm 3.4)$ & $0.142 \pm 0.032$ & $72.64 \pm 1.37$ \\
CT-NLC-3 & $3: 2$ & $188.8 \pm 17.1$ & $(31.0 \pm 2.3)$ & $0.196 \pm 0.037$ & $69.10 \pm 2.16$ \\
\hline
\end{tabular}

Note: Data represent means \pm standard deviation (SD).

Abbreviations: T-NLC, tripterine-loaded nanostructured lipid carrier; CT-NLC, CPP-coated T-NLC; CPP, cell-penetrating peptides; PDI, polydispersity index; $\mathrm{EE}$, entrapment efficiency. 

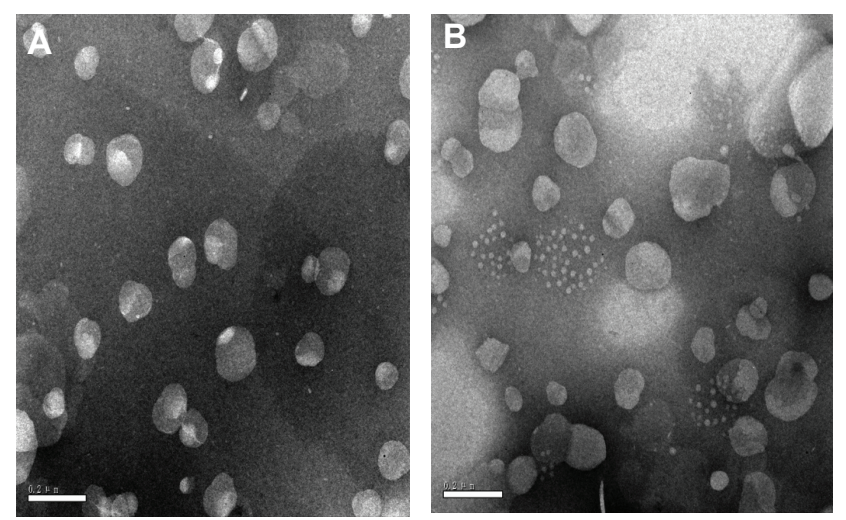

Figure I Transmission electron micrographs of the (A) T-NLC and (B) CT-NLC formulations.

Abbreviations: T-NLC, tripterine-loaded nanostructured lipid carrier; CT-NLC, cell-penetrating peptide-coated T-NLC.

$\left(164.5^{\circ} \mathrm{C}\right.$ and $\left.253.9^{\circ} \mathrm{C}\right)$. The thermogram of physical mixture I showed peaks caused by the superposition of the separated component curves at $40.9^{\circ} \mathrm{C}$ and $66.5^{\circ} \mathrm{C}$. The melting peak of tripterine at $211.4^{\circ} \mathrm{C}$ was also detected in physical mixture II; however, no melting peaks appeared in the mixture of tripterine with either T-NLCs or CT-NLCs. These results suggest that the drug was incorporated in the nanoparticle matrix in its amorphous or disordered, crystalline phase.

\section{In vitro drug release}

The in vitro release profiles of the CT-NLCs and T-NLCs are shown in Figure 3. After 24 hours, 40.41\% and 44.84\% of tripterine was released from the CT-NLCs and T-NLCs, respectively. By the end of the entire treatment period (48 hours), the percentage of released tripterine (Q) reached

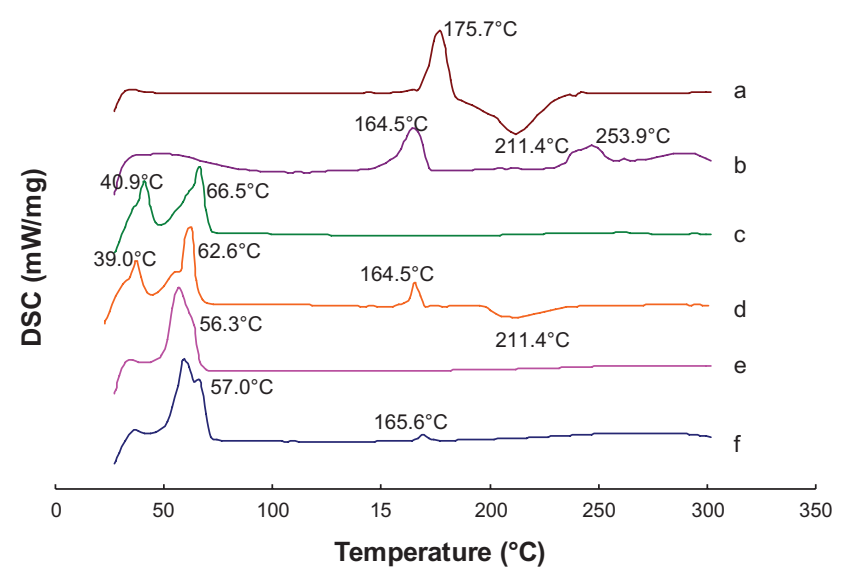

Figure 2 Differential scanning calorimetry curves of (a) tripterine, (b) CPP, (c) physical mixture I, (d) physical mixture II, (e) T-NLCs, and (f) CT-NLCs.

Abbreviations: CPP, cell-penetrating peptide; physical mixture I (Precirol ATO-5, Labrafil M 1944CS, soybean lecithin, DPGS, and F68); physical mixture II, physical mixture I + tripterine and CPP; T-NLCs, tripterine-loaded nanostructured lipid carriers; CT-NLC, CPP-coated T-NLC.

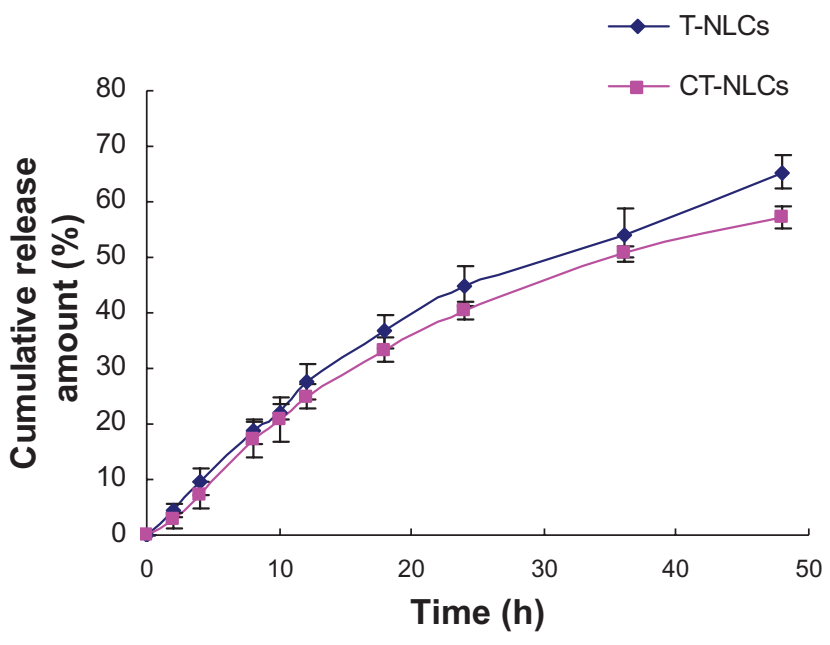

Figure 3 In vitro release profiles of tripterine from the T-NLCs and CT-NLCs. Note: Data represent means \pm standard deviation (SD).

Abbreviations: T-NLCs, tripterine-loaded nanostructured lipid carriers; CT-NLCs, cell-penetrating peptide-coated T-NLCs.

$65.40 \%$ for the T-NLCs and $57.30 \%$ for the CT-NLCs. Tripterine release followed the Higuchi equation and could be expressed as follows: $\mathrm{Q}=0.1031 \mathrm{t}^{1 / 2}-0.1172(\mathrm{r}=0.9974)$ and $\mathrm{Q}=0.1158 \mathrm{t}^{1 / 2}-0.1303(\mathrm{r}=0.9987)$ for the CT-NLCs and T-NLCs, respectively.

\section{In vitro cytotoxicity}

We determined the in vitro cytotoxicity of tripterine in CT-NLCs or T-NLCs formulation and compared it with that of tripterine solution by cell viability experiment. The results of cell viability and $\mathrm{IC}_{50}$ are shown in Figure 4 and Table 3, respectively. The viability of Caco-2 cells decreased significantly with an increase in the concentrations of the tripterine solutions, T-NLCs, and CT-NLCs. At the same dose, the viability of cells treated with

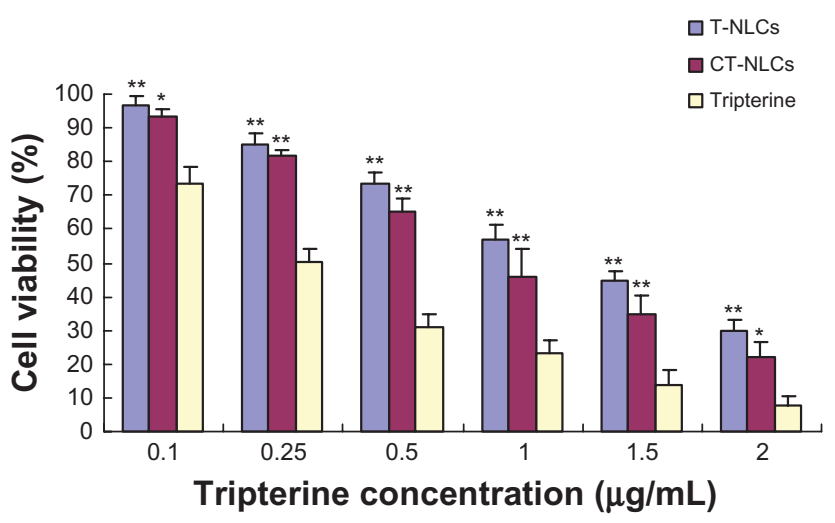

Figure 4 Results of the MTT assay with Caco-2 cells.

Notes: Data represent means \pm standard deviation (SD). $* P<0.05$, $* * P<0.01$ compared with the tripterine solution.

Abbreviations: T-NLCs, tripterine-loaded nanostructured lipid carriers; CT-NLCs, cell-penetrating peptide-coated T-NLCs. 
Table $3 \quad I C_{50}$ values of tripterine, T-NLCs, and CT-NLCs in Caco-2 cells

\begin{tabular}{ll}
\hline Group & IC $_{50}(\mu \mathrm{g} / \mathrm{mL})$ \\
\hline Tripterine & $0.316 \pm 0.037$ \\
T-NLCs & $1.171 \pm 0.098^{*}$ \\
CT-NLCs & $0.885 \pm 0.094^{*}$, \\
\hline
\end{tabular}

Notes: Data represent means \pm standard deviation (SD). $* P<0.05$ compared with tripterine; ${ }^{\dagger} P<0.05$ compared with T-NLCs.

Abbreviations: $I \mathrm{I}_{50}$, half-maximal inhibitory concentration; T-NLCs, tripterine-loaded nanostructured lipid carriers; CT-NLCs, cell-penetrating peptide-coated T-NLCs.

CT-NLCs was lower than that of the cells treated with T-NLCs, but was markedly higher than the viability of cells treated with tripterine $\operatorname{solution}(P<0.05)$. A substantial decrease was noted in the viability of cells treated with tripterine especially at a high concentration $(2 \mu \mathrm{g} /$ $\mathrm{mL}, 92.20 \%$ dead) compared with those treated with the CT-NLCs $(77.76 \%$ dead) and T-NLCs $(70.30 \%$ dead). The $\mathrm{IC}_{50}$ values of the tripterine solution, T-NLCs, and CTNLCs were $0.316 \pm 0.037 \mu \mathrm{g} / \mathrm{mL}, 1.171 \pm 0.098 \mu \mathrm{g} / \mathrm{mL}$, and $0.885 \pm 0.094 \mu \mathrm{g} / \mathrm{mL}$, respectively. The $\mathrm{IC}_{50}$ values of CT-NLCs and T-NLCs were higher than those of the tripterine solution $(P<0.05)$.

\section{Cellular uptake}

Uptake of tripterine from the CT-NLCs and T-NLCs by Caco-2 cells is shown in Figure 5. Uptake of tripterine was slightly, but consistently, higher from the CT-NLCs $(32.48 \%$, $53.84 \%, 66.52 \%$, and $73.11 \%$ ) than from the T-NLCs at all four time points $(27.93 \%, 43.58 \%, 65.83 \%$, and $65.83 \%$ after $1,2,3$, and 4 hours, respectively).

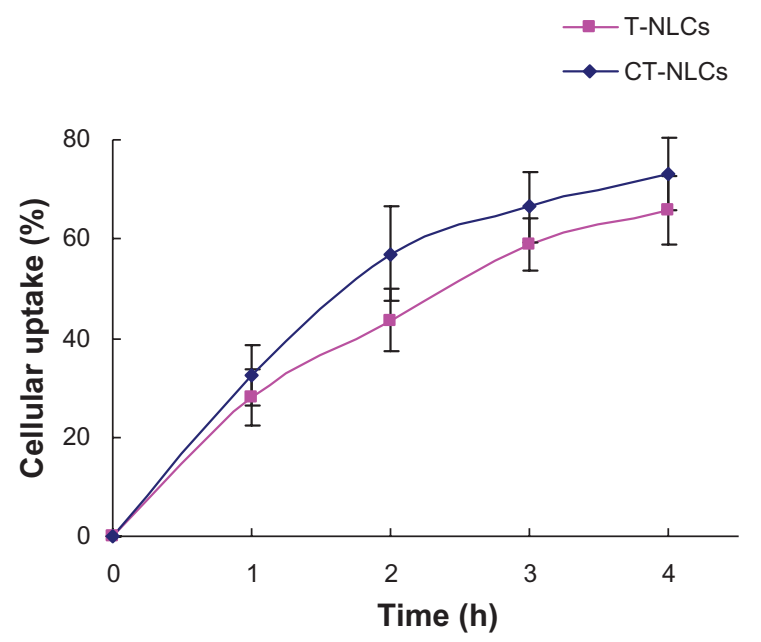

Figure 5 Cellular uptake of tripterine from the CT-NLCs and T-NLCs. Abbreviations: T-NLCs, tripterine-loaded nanostructured lipid carriers; CT-NLCs, cell-penetrating peptide-coated T-NLCs.
A

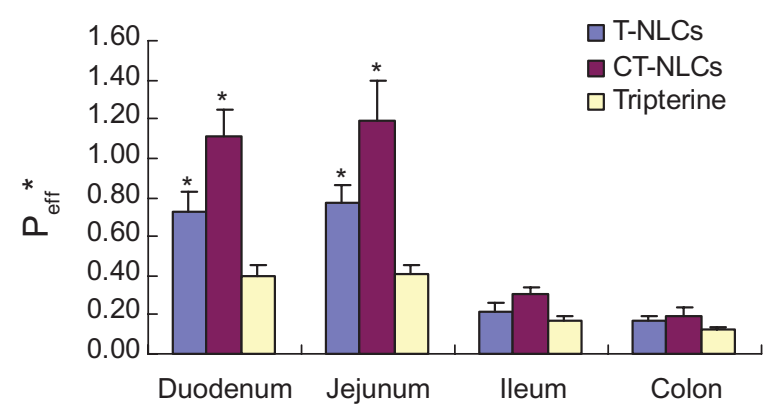

B

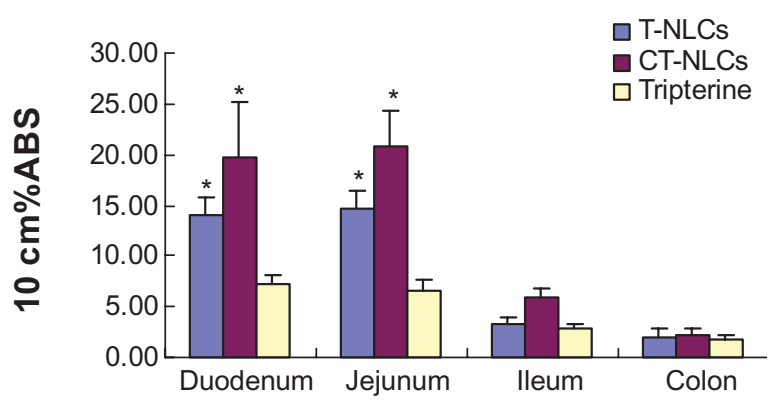

Figure 6 Results of the in situ rat intestinal absorption assay. (A) $P_{\text {eff }}^{*}$ and (B) $10 \mathrm{~cm} \% A B S$ of tripterine, T-NLCs, and CT-NLCs in 4 intestinal segments.

Notes: Data represent means \pm standard deviation $(n=4)$. $* p<0.05$ compared with the control.

Abbreviations: $P_{\text {eff }}{ }^{*}$, effective permeability; $10 \mathrm{~cm} \% \mathrm{ABS}$, percent absorption of $10 \mathrm{~cm}$ of intestine; T-NLCs, tripterine-loaded nanostructured lipid carriers; CT-NLCs, cell-penetrating peptide-coated T-NLCs.

\section{Intestinal absorption}

The $P_{\text {eff }}^{*}$ and $10 \mathrm{~cm} \%$ ABS values of the CT-NLCs, T-NLCs, and tripterine solution are shown in Figure 6. These values indicated that the absorption of tripterine from the CT-NLCs and T-NLCs in the four intestinal segments was better than that from the tripterine solution. The $P_{\text {eff }} *$ of the CT-NLCs was $1.115 \pm 0.137,1.193 \pm 0.206,0.304 \pm 0.038$, and $0.197 \pm 0.075$ in the duodenum, jejunum, ileum, and colon, respectively. These values were 2.8- and 2.9-fold higher than those of the tripterine solution, and approximately 1.5 times higher than that those of the T-NLCs in the duodenum and jejunum. Moreover, the absorption of the CT-NLCs, T-NLCs, and tripterine solution was better in the duodenum and jejunum than in the ileum and colon. Similar to the results of $P_{\text {eff }}{ }^{*}$, the $10 \mathrm{~cm} \%$ ABS values of the CT-NLCs in the duodenum and jejunum were 3.0- and 3.3-fold higher than those of the tripterine solution (Figure 6) and approximately 1.5 times higher than those of the T-NLCs. 
Table 4 Pharmacokinetic parameters of tripterine after oral administration of the tripterine suspension, T-NLCs, and CT-NLCs in beagles

\begin{tabular}{llllcrc}
\hline Formulation & $\mathbf{C}_{\max }(\mu \mathbf{g} / \mathbf{L})$ & $\mathbf{T}_{\max }(\mathbf{h})$ & $\mathbf{t}_{1 / 2} \mathbf{( h )}$ & AUC $_{(0-\mathrm{t})}(\mu \mathrm{g} / \mathrm{L} \cdot \mathbf{h})$ & AUC $_{(0-\infty)}(\mu \mathrm{g} / \mathbf{L} \cdot \mathbf{h})$ & $\mathbf{M R T}(\mathbf{h})$ \\
\hline Tripterine suspension & $223.73 \pm 31.55$ & $0.96 \pm 0.10$ & $1.60 \pm 0.13$ & $482.45 \pm 57.52$ & $625.75 \pm 66.39$ & $1.65 \pm 0.13$ \\
T-NLCs & $305.02 \pm 35.40$ & $2.33 \pm 0.58$ & $3.85 \pm 0.94$ & $1560.05 \pm 58.50$ & $1791.97 \pm 57.10$ & $4.37 \pm 0.33$ \\
CT-NLCs & $483.02 \pm 15.38$ & $1.67 \pm 0.58$ & $3.09 \pm 0.54$ & $2338.68 \pm 217.80$ & $2568.02 \pm 343.40$ & $4.08 \pm 0.37$ \\
\hline
\end{tabular}

Abbreviations: T-NLCs, tripterine-loaded nanostructured lipid carriers; CT-NLCs, cell-penetrating peptide-coated T-NLCs; $\mathrm{C}_{\max }$, maximum plasma concentration; $T_{\text {max }}$, time to $C_{\max } ; t_{1 / 2}$, elimination half-life; $A \cup C_{(0-t)}$, area under the concentration-time curve from 0 to $t$ hours; $A \cup C_{(0-\infty)}$, area under the concentration-time curve from 0 hours to infinity; MRT, mean residence time.

\section{Oral bioavailability}

We observed a remarkable increase in the plasma concentration of tripterine after treatment with CT-NLCs. The pharmacokinetic parameters are listed in Table 4. The mean tripterine plasma concentration versus time plots of the T-NLCs, CT-NLCs, and tripterine suspension are shown in Figure 7. The maximum plasma concentration of the CTNLCs $(483.02 \pm 15.38 \mu \mathrm{g} / \mathrm{L}))$ was greater than that of the tripterine suspension $(223.73 \pm 31.55 \mu \mathrm{g} / \mathrm{L})$ and T-NLCs $(305.02 \pm 35.40 \mu \mathrm{g} / \mathrm{L})$. The time to maximum plasma concentration $\left(\mathrm{T}_{\max }\right)$ of tripterine ( $0.96 \pm 0.10$ hours) was the shortest followed by that of CT-NLCs $(1.67 \pm 0.58$ hours $)$ and T-NLCs $(2.33 \pm 0.58$ hours $)$. The elimination half life of the CT-NLCs $(3.09 \pm 0.54$ hours $)$ and T-NLCs (3.85 \pm 0.94 hours) was longer than that of the tripterine suspension (1.60 \pm 0.13 hours). The mean residence time of the CT-NLCs and T-NLCs were approximately 2.5 times higher than that of the tripterine suspension $(P<0.05)$. The $\mathrm{AUC}_{(0-t)}$ of the CT-NLCs was 4.8-fold higher than that of the tripterine suspension, and 1.5-fold higher than that of

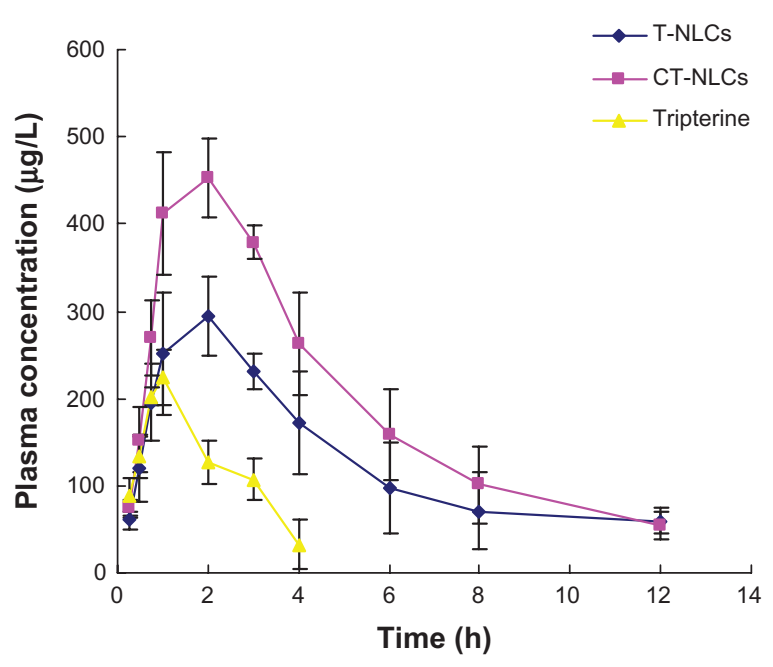

Figure 7 Plasma concentration profile of tripterine after the oral administration of the CT-NLCs, T-NLCs, and tripterine in beagles $(n=6)$.

Abbreviations: T-NLCs, tripterine-loaded nanostructured lipid carriers; CT-NLCs, cell-penetrating peptide-coated T-NLCs. the T-NLCs. The relative bioavailability of tripterine from CT-NLCs and T-NLCs was $484.75 \%$ and $309.25 \%$ compared with that from the tripterine suspension, respectively, and the relative bioavailability of tripterine from CT-NLCs was $149.91 \%$, compared with that from T-NLCs.

\section{Discussion}

CPPs are useful tools in developing lipid nanoparticles. ${ }^{20,31}$ Ste- $\mathrm{R}_{6} \mathrm{~L}_{2}$ is a kind of CPP, which has short amino acid sequences that are mainly composed of arginine and leucine. Ste- $\mathrm{R}_{6} \mathrm{~L}_{2}$ has cationic properties and thus it can easily adhere to the NLC surfaces on the basis of electrostatic interactions. In the current study, the zeta potential of the nanoparticle dispersion was reversed after coating with the CPP. The findings of Zhang et $\mathrm{al}^{20}$ were similar to ours in that the positive value of zeta potential of SLNs loaded with insulin and $\mathrm{R}_{8}\left(\mathrm{R}_{8}\right.$-Ins-SLNs) confirmed that a certain amount of $\mathrm{R}_{8}$ (a type of CPPs) molecule or cationic group of $\mathrm{R}_{8}$ molecule was exposed on the surface of the SLNs. In addition, the stearyl group of Ste- $\mathrm{R}_{6} \mathrm{~L}_{2}$ can attach to the N-terminal of the peptide and act as an anchor to the lipid surface of the nanoparticles, which leaves the Ste- $\mathrm{R}_{6} \mathrm{~L}_{2}$ freely attached. In this study, CPP-coated NLCs were successfully developed, and they increased the intestinal absorption and oral bioavailability of tripterine.

Particle size, PDI, and zeta potential are important physicochemical properties associated with the stability and acceptability of a drug delivery system. The particle size of the CT-NLCs increased with different amounts of the CPP coating, but the $\mathrm{CPP} /$ tripterine ratios of 1:2 and 2:2 led to only a slight increase in the particle size. Surface modification of nanoparticles was finally assessed by zeta potential. The negative zeta potential of the T-NLCs was reversed after coating with the CPP. The $\mathrm{CPP} /$ tripterine ratio of $2: 2$ resulted in a zeta potential close to $30 \mathrm{mV}$, which signified the fine stability of the aqueous dispersion. ${ }^{31}$ The PDIs of both the CTNLCs and the T-NLCs were lower than 0.2 , which indicated their good size distribution..$^{32}$ The $\% \mathrm{EE}$ of tripterine in the CT-NLCs was slightly lower than that in the T-NLCs, but no 
significant changes were noted for CT-NLC-1 and CT-NLC-2. On the basis of the zeta potentials, PDIs, and \%EEs of the three CT-NLC formulations, CT-NLC-2 was selected as the optimized formulation because of its small size and good stability.

The in vitro drug-release results indicated that tripterine release from the CT-NLCs and T-NLCs followed the Higuchi equation, and a slightly slower release speed was obtained with the CT-NLCs. This implied that tripterine could be released slowly from both formulations and be maintained at a constant concentration for a relatively long period. The delayed release process might be attributed to the drug lipophilicity, high hydrophobicity of the lipid matrix, and/or prevention of drug diffusion from the NLCs by the lipid matrix. ${ }^{12}$ The slightly slower release of tripterine from the CT-NLCs than from the T-NLCs may be due to particle size; in particular, the increased size of the CT-NLC particles may have been associated with a smaller specific surface area of nanoparticles, which may have led to a decreased release rate. ${ }^{33}$

The results of the MTT assay indicated that cytotoxicity was dose dependent over a range of drug concentrations. In terms of $\mathrm{IC}_{50}$, the CT-NLCs and T-NLCs greatly decreased the cytotoxicity of tripterine. The results showed that the NLC formulations could decrease the intestinal toxicity of tripterine and reduce its side effects in the GIT. The reason for the low cytotoxicity could be that tripterine in both the formulations was completely associated with nanoparticles and released in a controlled manner over 24 hours. ${ }^{34}$ The cellular uptake of the CT-NLCs was higher than that of the T-NLCs. This result could be related to the properties of the CPP, which is composed mainly of arginine and leucine residues, which confer a positive charge to the nanoparticles; nanoparticle uptake is enhanced by interactions between the CPP and the negatively charged components of the cell membrane. ${ }^{35}$ Although the mechanism(s) involved in the transport of CPPs and their cargos across endomembranes are still poorly understood, two major mechanisms have been mainly considered: endosomal pathways consisting of two steps, endocytotic entry followed by endosomal escape; and direct cell membrane penetration. ${ }^{22}$ We speculate that CPPs of Ste- $\mathrm{R}_{6} \mathrm{~L}_{2}$, by interacting with the cell membrane and destabilizing the bilayer, may be capable of carrying the nanoparticles across by endocytotic entry or direct cell membrane penetration. The high cellular uptake resulted in slightly higher cytotoxicity of the CT-NLCs than of the T-NLCs.

The intestinal absorption of the CT-NLCs and T-NLCs was markedly higher than that of the tripterine solution. This result indicated that the NLCs clearly enhanced the absorption of tripterine in the intestine, and this effect was especially improved when the particles were coated with the CPP. The low absorption of tripterine may be attributable to its poor water solubility, and the physicochemical barrier formed by the GIT and intestinal epithelium. Therefore, the improved absorption of tripterine in the T-NLCs and CT-NLCs could be explained as follows: a smaller particle size enables permeation of the drug across the cell membranes, and/or an affinity exists between the lipid material used here and the cell membrane. ${ }^{29}$ The CT-NLCs showed higher absorption than the T-NLCs, and the $P_{\text {eff }}{ }^{*}$ of tripterine in the duodenum and jejunum was $>1,{ }^{36}$ which indicated good absorption of the CT-NLCs. CPPs have been successfully used in both cell cultures and animal models. ${ }^{37}$ These results can be explained by the high positive charge density of the CPP, which would have high electrostatic interaction with the negatively charged cell surfaces. ${ }^{38}$ This binding facilitates endocytosis and direct penetration. Furthermore, the internalization efficiency of the CPP itself may have affected the intestinal absorption of the CT-NLCs, so that the CT-NLCs could be internalized into the epithelium via an energy-dependent pathway, which could enhance the intestinal absorption of NLCs.

The enhanced intestinal absorption led to a dramatic increase in the oral bioavailability of the CT-NLCs. The $\mathrm{AUC}_{(0-\mathrm{t})}$ values indicated the enhanced effects of the CTNLCs on the oral absorption of tripterine. Moreover, a prolonged $\mathrm{T}_{\max }$ is generally believed to be responsible for the slow release of a drug from nanoparticles. The CT-NLCs had a large $\mathrm{T}_{\max }$ and could avoid the initial burst of tripterine as well as prolong the dose interval, which could possibly reduce the clinical side effects of tripterine. In previous studies, NLCs have been used to enhance the half-life and solubility of drugs. ${ }^{29}$ However, the absorption of nanoparticles continued to be limited only via the transcellular pathway by $\mathrm{M}$ cells in Peyer's patches or by pinocytosis. ${ }^{15}$ When we combined NLCs with CPPs, the bioavailability was improved. This might be because of the various favorable characteristics of CPPs, especially the cationic nature. CPPs have been used to enhance the delivery of various types of nanocarriers, both in cell culture and in animal models. ${ }^{37} \mathrm{CPPs}$ might bind to electrostatic membrane constituents, such as anionic lipids and glycosaminoglycans. Then, their cargos might travel across membranes by endocytosis or direct penetration, to increase bioavailability of drug. Although the mechanism of the CPP-linked NLCs on enhanced oral bioavailability has not been elucidated at this stage of study, a few assumptions have been made about the absorption mechanisms of the CT-NLCs. 
Multiple mechanisms, rather than a single one, including enhanced contraction with cell surfaces, transportation of CPP-linked nanoparticles across cell membranes, ${ }^{39}$ and enhanced absorption through the lipid digestion process, may contribute to enhanced oral bioavailability of tripterine. ${ }^{40}$

\section{Conclusion}

A novel CT-NLC formulation was prepared; the characteristics of this formulation indicate that it has great potential to improve the oral delivery of poorly soluble drugs. Results showed that CT-NLCs could remarkably enhance the absorption and bioavailability of tripterine, which indicated that CT-NLCs are superior to T-NLCs in improving the oral bioavailability of tripterine, and are a promising system for oral delivery of tripterine.

\section{Acknowledgments}

This study received financial support from the Natural Science Foundation of Jiangsu Province (No BK2010593) and the Jiangsu Provincial Chinese Medicine Leading Talent Project (No LJ200913).

\section{Disclosure}

The authors report no conflicts of interest in this work.

\section{References}

1. Jang SY, Jang SW, Ko J. Celastrol inhibits the growth of estrogen positive human breast cancer cells through modulation of estrogen receptor $\alpha$. Cancer Lett. 2011;300(1):57-65.

2. Ríos JL. Effects of triterpenes on the immune system. J Ethnopharmacol. 2010;128(1):1-14.

3. Kim DY, Park JW, Jeoung D, Ro JY. Celastrol suppresses allergeninduced airway inflammation in a mouse allergic asthma model. Eur $J$ Pharmacol. 2009;612(1-3):98-105.

4. Setty AR, Sigal LH. Herbal medications commonly used in the practice of rheumatology: mechanisms of action, efficacy, and side effects. Semin Arthritis Rheum. 2005;34(6):773-784.

5. Kannaiyan R, Shanmugam MK, Sethi G. Molecular targets of celastrol derived from Thunder of God Vine: potential role in the treatment of inflammatory disorders and cancer. Cancer Lett. 2011;303(1):9-20.

6. Salminen A, Lehtonen M, Paimela T, Kaarniranta K. Celastrol: molecular targets of Thunder God Vine. Biochem Biophys Res Commun. 2010;394(3):439-442.

7. Huang Y, Zhou D, Hang T, et al. Preparation, characterization, and assessment of the antiglioma effects of liposomal celastrol. Anticancer Drugs. 2012;23(5):515-524.

8. Yang F, Dong XG, An ZM, et al. Retrospect and prospect of studies on Tripterygium wilfordii Hook f. Chin J Integr Med. 2005; 11(2):89-96.

9. Liu Z, Ma L, Zhou GB. The main anticancer bullets of the Chinese medicinal herb, thunder god vine. Molecules. 2011;16(6):5283-5297.

10. Dai Y, DeSano J, Tang W, et al. Natural proteasome inhibitor celastrol suppresses androgen-independent prostate cancer progression by modulating apoptotic proteins and NF-kappaB. PLoS One. 2010;5(12):e14153.

11. Das $S$, Chaudhury A. Recent advances in lipid nanoparticle formulations with solid matrix for oral drug delivery. AAPS Pharm Sci Tech. 2011;12(1):62-76.
12. Gonzalez-Mira E, Nikolić S, Calpena AC, Egea MA, Souto EB, García ML. Improved and safe transcorneal delivery of flurbiprofen by NLC and NLC-based hydrogels. J Pharm Sci. 2012;101(2): 707-725.

13. Severino P, Andreani T, Macedo AS, et al. Current state-of-art and new trends on lipid nanoparticles (SLN and NLC) for oral drug delivery. J Drug Deliv [serial on the internet]. 2012;Article ID 75891. Available from: http://www.hindawi.com/journals/jdd/2012/750891/. Accessed July 30, 2012.

14. Zhou L, Chen Y, Zhang Z, He J, Du M, Wu Q. Preparation of tripterine nanostructured lipid carriers and their absorption in rat intestine. Pharmazie. 2012;67(4):304-310.

15. Des Rieux A, Fievez V, Momtaz M, et al. Helodermin-loaded nanoparticles: characterization and transport across an in vitro model of the follicle-associated epithelium. J Control Release. 2007;118(3): 294-302.

16. Bolhassani A. Potential efficacy of cell-penetrating peptides for nucleic acid and drug delivery in cancer. Biochim Biophys Acta. 2011;1816(2):232-246.

17. Deshayes S, Morris MC, Divita G, Heitz F. Cell-penetrating peptides: tools for intracellular delivery of therapeutics. Cell Mol Life Sci. 2005;62(16):1839-1849.

18. Dietz GP. Protection by neuroglobin and cell-penetrating peptidemediated delivery in vivo: a decade of research. Comment on Cai et al: TAT-mediated delivery of neuroglobin protects against focal cerebral ischemia in mice. Exp Neurol. 2011;227(1):224-231. Exp Neurol. 2011;231(1):1-10.

19. Said Hassane F, Saleh AF, Abes R, Gait MJ, Lebleu B. Cell penetrating peptides: overview and applications to the delivery of oligonucleotides. Cell Mol Life Sci. 2010;67(5):715-726.

20. Zhang Z, Lv H, Zhou J. Novel solid lipid nanoparticles as carriers for oral administration of insulin. Pharmazie. 2009;64(9):574-578.

21. Kibria G, Hatakeyama H, Harashima H. A new peptide motif present in the protective antigen of anthrax toxin exerts its efficiency on the cellular uptake of liposomes and applications for a dual-ligand system. Int J Pharm. 2011;412(1-2):106-114.

22. Madani F, Lindberg S, Langel U, Futaki S, Gräslund A. Mechanisms of cellular uptake of cell-penetrating peptides. J Biophys [serial on the internet]. 2011; Article ID 414729. Available from: http://www.hindawi. com/journals/jbp/2011/414729/. Accessed July 30, 2012.

23. Järver P, Langel $\mathrm{U}$. The use of cell-penetrating peptides as a tool for gene regulation. Drug Discov Today. 2004;9(9):395-402.

24. Varma MV, Panchagnula R. Enhanced oral paclitaxel absorption with vitamin E-TPGS: effect on solubility and permeability in vitro, in situ and in vivo. Eur J Pharm Sci. 2005;25(4-5):445-453.

25. Liu D, Liu Z, Wang L, Zhang C, Zhang N. Nanostructured lipid carriers as novel carrier for parenteral delivery of docetaxel. Colloids Surf B Biointerfaces. 2011;85(2):262-269.

26. Nehilla BJ, Allen PG, Desai TA. Surfactant-free, drug-quantum-dot coloaded poly(lactide-co-glycolide) nanoparticles: towards multifunctional nanoparticles. ACS Nano. 2008;2(3):538-544.

27. Chen Y, Wang J, Yuan L, Zhou L, Jia X, Tan X. Interaction of the main components from the traditional Chinese drug pair Chaihu-Shaoyao based on rat intestinal absorption. Molecules. 2011;16(11):9600-9610.

28. Lai J, Lu Y, Yin Z, Hu F, Wu W. Pharmacokinetics and enhanced oral bioavailability in beagle dogs of cyclosporine A encapsulated in glyceryl monooleate/poloxamer 407 cubic nanoparticles. Int J Nanomedicine. 2010;5:13-23.

29. Zhuang CY, Li N, Wang M, et al. Preparation and characterization of vinpocetine loaded nanostructured lipid carriers (NLC) for improved oral bioavailability. Int J Pharm. 2010;394(1-2):179-185.

30. Torchilin VP. Multifunctional nanocarriers. Adv Drug Deliv Rev. 2006; 58(14):1532-1555.

31. Marquele-Oliveira F, Santana DC, Taveira SF, et al. Development of nitrosyl ruthenium complex-loaded lipid carriers for topical administration: improvement in skin stability and in nitric oxide release by visible light irradiation. J Pharm Biomed Anal. 2010;53(4):843-851. 
32. Klang V, Matsko N, Zimmermann AM, Vojnikovic E, Valenta C. Enhancement of stability and skin permeation by sucrose stearate and cyclodextrins in progesterone nanoemulsions. Int J Pharm. 2010;393(1-2):152-160.

33. Jia LJ, Zhang DR, Li ZY, et al. Preparation and characterization of silybin-loaded nanostructured lipid carriers. Drug Deliv. 2010; 17(1):11-18.

34. Saravanakumar G, Min KH, Min DS, et al. Hydrotropic oligomerconjugated glycol chitosan as a carrier of paclitaxel: synthesis, characterization, and in vivo biodistribution. J Control Release. 2009;140(3): 210-217.

35. Hirose H, Takeuchi T, Osakada H, et al. Transient focal membrane deformation induced by arginine-rich peptides leads to their direct penetration into cells. Mol Ther. 2012;20(5):984-993.

36. Liu Y, Hu M. Absorption and metabolism of flavonoids in the caco-2 cell culture model and a perused rat intestinal model. Drug Metab Dispos. 2002;30(4):370-377.
37. Zahid M, Lu X, Mi Z, Robbins PD. Cationic and tissue-specific protein transduction domains identification, characterization, and therapeutic application. Adv Genet. 2010;69:83-95.

38. Ziegler A. Thermodynamic studies and binding mechanisms of cellpenetrating peptides with lipids and glycosaminoglycans. Adv Drug Deliv Rev. 2008;60(4-5):580-597.

39. Foged C, Nielsen HM. Cell-penetrating peptides for drug delivery across membrane barriers. Expert Opin Drug Deliv. 2008;5(1):105-117.

40. O'Driscoll CM, Griffin BT. Biopharmaceutical challenges associated with drugs with low aqueous solubility - the potential impact of lipidbased formulations. Adv Drug Deliv Rev. 2008;60(6):617-624.
International Journal of Nanomedicine

\section{Publish your work in this journal}

The International Journal of Nanomedicine is an international, peerreviewed journal focusing on the application of nanotechnology in diagnostics, therapeutics, and drug delivery systems throughout the biomedical field. This journal is indexed on PubMed Central,

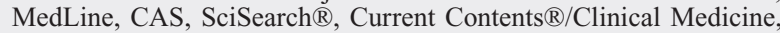

\section{Dovepress}

Journal Citation Reports/Science Edition, EMBase, Scopus and the Elsevier Bibliographic databases. The manuscript management system is completely online and includes a very quick and fair peer-review system, which is all easy to use. Visit http://www.dovepress.com/ testimonials.php to read real quotes from published authors.

Submit your manuscript here: http://www.dovepress.com/international-journal-of-nanomedicine-journal 